\title{
CARACTERIZACIÓN ECOLÓGICA Y DIVERSIDAD DE LOS BOSQUES DE ENCINO DE LA SIERRA DE ZAPALINAMÉ, COAHUILA, MÉXICO
}

\author{
Juan A. Encina-Domínguez ${ }^{1,3}$, Alejandro Zárate-Lupercio', Jesús Valdés-Reyna² \\ Y JosÉ A. VILLARREAL-QUINTANILLA \\ Universidad Autónoma Agraria Antonio Narro \\ 'Departamento Forestal, Laboratorio de Sistemas de Información Geográfica \\ ${ }^{2}$ Departamento de Botánica \\ Buenavista, Saltillo 25315, Coahuila, México. \\ ${ }^{3}$ Autor para la correspondencia. Correo-e: juanencina@gmail.com
}

\begin{abstract}
Resumen: La sierra de Zapalinamé es un área natural protegida del sureste de Coahuila, en la transición entre el Desierto Chihuahuense y la Sierra Madre Oriental. En sus cañones, donde el clima es templado subhúmedo y templado semiseco, se desarrollan bosques de encino. Con la finalidad de conocer la distribución, la riqueza y la diversidad de especies de estos bosques, se establecieron 66 sitios circulares de $500 \mathrm{~m}^{2}$, donde se tomó información de la densidad, el diámetro y la cobertura de las plantas leñosas, y de la frecuencia de las hierbas. Se utilizó la densidad de plantas leñosas y la frecuencia de todos los gremios de plantas para calcular el índice de diversidad de Shannon-Wiener; la relación entre la diversidad y la riqueza de especies leñosas con las variables ambientales se analizó mediante regresión lineal. Se reconocieron dos asociaciones del encinar: bosque de Quercus greggii-Q. mexicana y bosque de $Q$. saltillensis-Q. laeta, ambos distribuidos en un intervalo altitudinal de 2,000 a $2,600 \mathrm{~m}$. La precipitación media es de $324 \mathrm{~mm}$ y la temperatura media es de $16^{\circ} \mathrm{C}$. Los bosques de $Q$. saltillensis-Q. laeta presentan el índice de diversidad más alto, así como la mayor riqueza de hierbas y arbustos, debido a las condiciones ambientales particulares, a la mayor incidencia de disturbios antropogénicos y a la infiltración de especies provenientes del matorral submontano. El patrón de diversidad de especies y su relación con los gradientes ambientales muestra que la diversidad y la riqueza disminuyen con el aumento de altitud y de precipitación, pero que aumentan con el incremento de la temperatura. En estos encinares la riqueza de especies varía marcadamente, siendo las hierbas las de mayor riqueza, seguidas por los arbustos y al final los árboles. La diversidad alfa promedio para las parcelas de muestreo fue de 40 especies. El patrón en la diversidad parece resultar de una combinación de procesos ecológicos con la configuración espacial y el historial de manejo del área protegida. En el diseño de estrategias de conservación biológica se deberá considerar el control de los disturbios antropogénicos.
\end{abstract}

Palabras clave: bosque de encino, diversidad de especies vegetales, disturbio antropogénico, gradiente ambiental, riqueza de especies vegetales.

\begin{abstract}
The sierra de Zapalinamé is a natural protected area located at the southeastern portion of Coahuila state. It represents a transitional area between the Chihuahuan Desert and the Sierra Madre Oriental. The oak forest thrives in canyons with temperate climate. In order to determine the distribution, richness and diversity of species in these forests, sixty-six $500 \mathrm{~m}^{2}$-circular plots were established in which information on density, tree diameter, woody species cover and herb frequency was gathered. Density of shrubs and frequency of all species were used to evaluate diversity through the Shannon-Wiener index, and the relationship between diversity and some environmental factors was examined with linear regression. Two associations were recognized: the Quercus greggii-Q. mexicana association, and the $Q$. saltillensis-Q. laeta association, both growing between 2,000 to $2600 \mathrm{~m}$ elevation. Mean total annual rainfall is $324 \mathrm{~mm}$ and mean temperature is $16^{\circ} \mathrm{C}$. The $Q$. saltillensis $-Q$. laeta forest was the most diverse; its high shrub and herb richness is due to the particular environmental conditions, incidence of human disturbance, and species infiltration from the neighboring piedmont scrub. The relationship between environmental conditions and diversity patterns shows that species diversity decreases as elevation and precipitation increase, but that it increases with temperature. The oak forest displays a large variability in its diversity: the herbs were the richest group, followed by shrubs and finally by trees. Mean alfa diversity was 40 plants by plot. The observed diversity pattern derives from a combination of ecological process, spatial configuration, and the historical management of the area. Future conservation strategies should consider the control of the human disturbances.
\end{abstract}

Key words: environmental gradient, human disturbance, oak forest, plant species diversity, species plant richness. 
$\mathbf{M}$ éxico es el tercer país con mayor diversidad biológica en el mundo (Toledo y Ordoñez, 1993), debido a su ubicación geográfica y a la combinación de una variedad de condiciones fisiográficas y climáticas, además de su compleja historia geológica (Flores-Villela y Gerez, 1994). Los bosques de coníferas y de encino ocupan $21 \%$ de la superficie del país y tienen una riqueza florística de unas 7,000 especies, de las cuales $70 \%$ son endémicas (Rzedowski, 1991). Por esta razón, se ha propuesto que es la comunidad terrestre con mayor riqueza de taxa endémicos en el país (Toledo y Ordoñez, 1993).

Los bosques templados y tropicales, y los matorrales de climas secos del hemisferio norte, están ampliamente distribuidos en los macizos montañosos de México. Los bosques de encino cubren aproximadamente $5.5 \%$ de la superficie total del país, encontrándose la mayor diversidad de especies del género Quercus L. en el intervalo altitudinal de 1,200 a 2,800 m (Rzedowski, 1978). México es el centro de diversidad de los encinos en el hemisferio occidental (Nixon, 1993); en el país se han registrado 161 especies, de las cuales 109 son endémicas (Valencia-A., 2004). Para el estado de Coahuila se citan 30 taxa específicos, de los cuales 14 se distribuyen en la Sierra de Zapalinamé y siete forman comunidades boscosas (Encina-Domínguez, 1996). Los encinos muestran una extensa amplitud ecológica. En México constituyen el principal componente fisonómico de los bosques de encino, pino-encino y mesófilo de montaña (Nixon, 1993). La composición florística de los encinares presenta una mezcla de elementos neotropicales y holárticos (en porcentajes más o menos equivalentes), además de una participación un poco menor de géneros autóctonos (Rzedowski, 1978).

En la actualidad, los ecosistemas terrestres de México presentan una drástica alteración y una reducción en su superficie original (Toledo y Ordoñez, 1993; Challenger, 1998). La degradación ecológica ha afectado a los encinares, por lo que algunos bosques han desaparecido debido a un aprovechamiento irracional o a cambios en el uso de la tierra, mientras que otros revelan fuertes daños en su estructura y afectaciones en su dinámica (Challenger, 1998). Ante esta situación, desde hace casi 30 años Rzedowski (1978) ya había sugerido fomentar la conservación de los encinares, en especial donde su presencia es necesaria para preservar el equilibrio ecológico de las cuencas.

La sierra de Zapalinamé es un área protegida, bajo la categoría de Zona Sujeta a Conservación Ecológica, decretada por el gobierno del estado de Coahuila (Anónimo, 1996). Esta definición tiene como justificación principal la protección, la conservación y el uso sustentable de los recursos naturales de la región. Los objetivos centrales de la reserva son la recarga de los acuíferos que abastecen de agua a la ciudad de Saltillo y la conservación de la biodiversidad (Anónimo, 1998). Este macizo montañoso ofrece un variado mosaico de microambientes debido a su topografía irregular, lo que ha favorecido el establecimiento de un elevado número de especies (Arce y Marroquín, 1983).

Por estas razones, es fundamental fomentar el conocimiento ecológico de las comunidades vegetales del área natural protegida. Como parte de esta investigación, es necesario conocer la composición florística y de los requerimientos ecológicos del bosque como unidad, con la finalidad de recuperar las áreas deterioradas y desarrollar programas de gestión sostenibles, y así garantizar la conservación de la diversidad biológica del macizo montañoso. El objetivo del presente estudio fue determinar y analizar la diversidad florística, la distribución y algunas variables físico-ecológicas como la altitud, la pendiente, la temperatura y la precipitación, así como la composición de especies vegetales asociadas a los bosques de encino de la Sierra de Zapalinamé.

\section{Región de estudio}

La sierra de Zapalinamé se localiza en el sureste de Coahuila, en la zona de transición entre el Desierto Chihuahuense y la Sierra Madre Oriental. Se trata de una estribación de la Provincia Fisiográfica de la Sierra Madre Oriental, en el noreste de México, la cual se extiende desde el centro del país. La sierra forma parte de los municipios de Saltillo y Arteaga y queda muy cerca de la ciudad de Saltillo (25 $15^{\prime} 00^{\prime \prime}-25^{\circ} 25^{\prime} 58.35^{\prime \prime}$ latitud N, 100 $47^{\circ} 14.5^{\prime \prime}$ - $101^{\circ} 05^{\prime} 3.8^{\prime \prime}$ longitud O; figura 1). La región pertenece a la Subprovincia de la Gran Sierra Plegada; el macizo incluye valles, planicies y elevaciones plegadas (Anónimo, 1998), y la orientación de los pliegues transversales es de este a oeste. Las altitudes van de $1,590 \mathrm{~m}$ en el pie de monte hasta 2,200 m en los valles intermontanos, alcanzando su mayor elevación a 3,140 m en el cerro El Penitente. La zona montañosa se encuentra disectada por cañones y presenta pendientes abruptas y topografía accidentada. Las rocas que afloran en el área son sedimentarias marinas del Jurásico y Cretácico; las calizas ocupan $43 \%$ del área y las areniscas y conglomerados, $17 \%$. Los suelos aluviales ocupan casi $30 \%$ del área, los suelos de tipo litosol $49 \%$, y los rendzina 29\%; en proporciones menores se localizan el xerosol cálcico y el feozem calcárico. El área se caracteriza, en general, por poseer un clima BSokw"(e); en las partes bajas de la zona es seco y templado, y templado en las altas. El clima se clasifica como cálido semi-frío; hacia la parte sur del macizo montañoso el clima es semiárido y en el sureste llega a ser subhúmedo. La temperatura media anual oscila entre 5 y $12^{\circ} \mathrm{C}$. La precipitación promedio es $498 \mathrm{~mm}$, siendo de tipo convectivo; las lluvias coinciden con los meses calientes del año. Durante los meses secos (octubre-abril), la precipitación varía entre 6 y $36 \mathrm{~mm}$, y en los meses húmedos (mayo-septiembre) el promedio mensual es de 78 mm (Anónimo, 1983). 
En general, la cubierta vegetal de las áreas con exposición sur está representada por matorrales rosetófilo y micrófilo. En las partes altas la vegetación está integrada por bosque de pino y oyamel, mientras que en los cañones se localizan bosques de encino y en las laderas bajas de exposición norte y oeste se presenta el matorral submontano de rosáceas (Marroquín, 1976). Los tipos de vegetación más extensos son el bosque de pino (14.1\% del área protegida), el bosque de piñonero (12.5\%) y el bosque de piño- nero con matorral xerófilo $(9.6 \%)$. En los cañones con mejores condiciones de humedad se desarrollan bosques de encino (Arce y Marroquín, 1983). Éstas son comunidades vegetales de porte bajo, con alturas entre 5 y $10 \mathrm{~m}$, de distribución irregular, con mayor frecuencia en altitudes entre 2,200 y $2,400 \mathrm{~m}$ sobre laderas medias y bajas. Predominan en exposiciones norte y oeste, con pendientes mayores o iguales a $30 \%$, y presentan una tendencia a desarrollarse sobre suelos someros y rocosos (Ramírez-M., 1998; Arce y

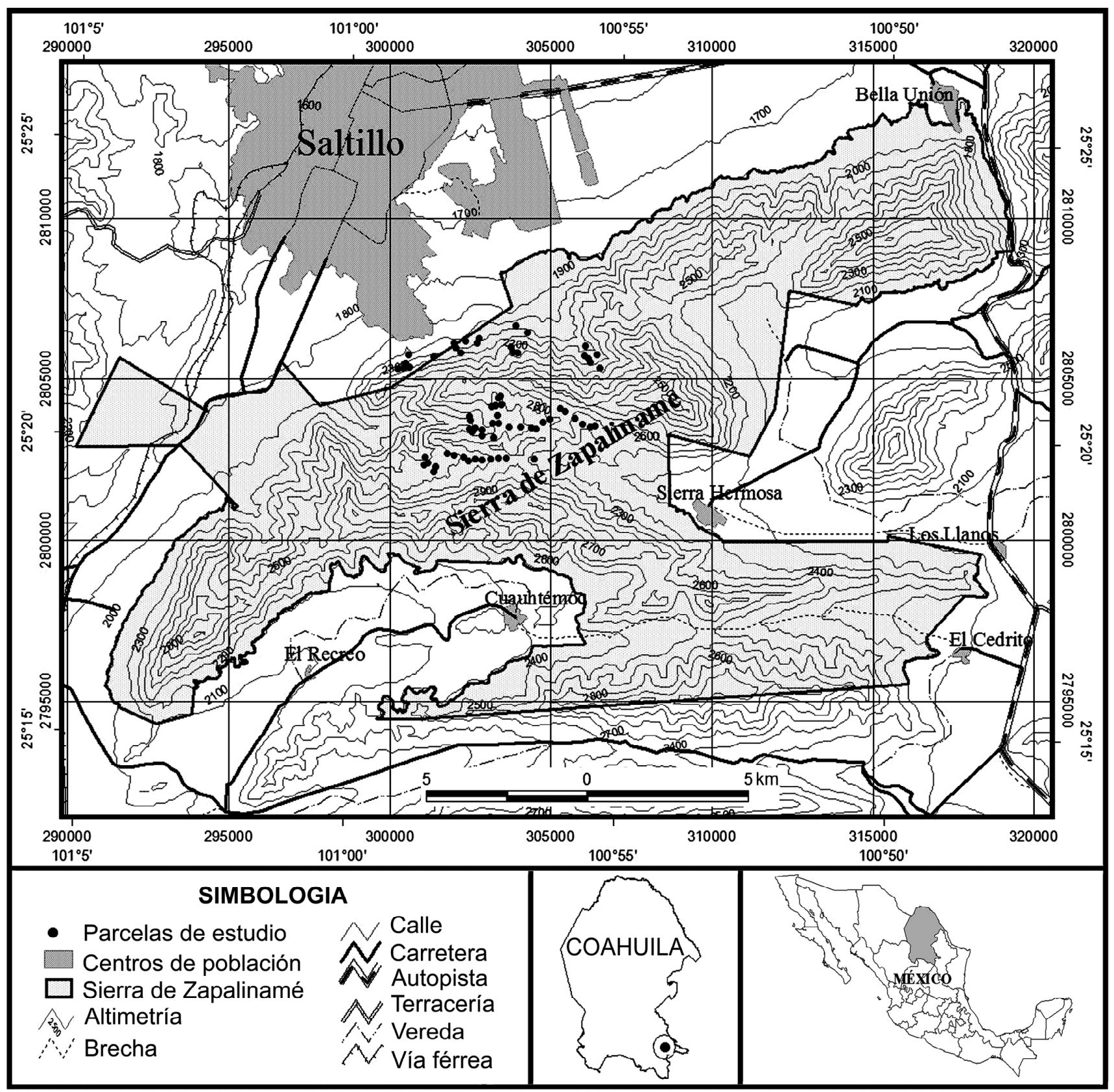

Figura 1. Localización de la Sierra de Zapalinamé y ubicación de las parcelas de estudio. 
Marroquín, 1983). El bosque mediano de encino se distribuye en la exposición noroeste de la Sierra y está formado por Quercus laeta Liebm. y Q. saltillensis Trel., con alturas de 2 a $5 \mathrm{~m}$; el estrato herbáceo tiene un alta riqueza de especies (Marroquín, 1976). Para la sierra de Zapalinamé se conocen 14 especies del género Quercus, por lo cual ésta es considerada un centro de diversidad de este género en Coahuila (Encina-Domínguez y Villarreal-Quintanilla, 2002). Destacan Quercus greggii (A.DC.) Trel., Q. mexica $n a$ Humb. et Bonpl., $Q$. saltillensis y $Q$. laeta. Estas especies forman encinares puros o mixtos con especies de los géneros Arbutus, Juniperus y Garrya, entre otros (EncinaDomínguez, 1996).

\section{Materiales y métodos}

Se establecieron 66 sitios de muestreo a través de los bosques de encino, siguiendo la compensación por pendiente (Medina, 1983). Las unidades de muestreo se ubicaron a una distancia constante entre sitios de $200 \mathrm{~m}$, a través de gradientes altitudinales, en los cañones donde hay bosques de encino. Para realizar las mediciones se utilizó el método con área (Mueller-Dombois y Ellenberg, 1974). Los sitios de muestreo fueron circulares, con un área de $500 \mathrm{~m}^{2}$ (Olvera-V. et al., 1996), en los que se cuantificaron las especies leñosas (arbustivas y arbóreas), midiendo el diámetro de los árboles a una altura de $1.30 \mathrm{~m}$ y la cobertura de los arbustos. Para el estrato herbáceo sólo se registraron las especies presentes. En los sitios de muestreo se tomó información sobre aspectos fisiográficos como altitud (tomada de un altímetro-barómetro), pendiente (con pistola Haga), posición topográfica con respecto a un plano horizontal de referencia, exposición topográfica tomada con una brújula y profundidad del suelo, utilizando una barrena de $1.5 \mathrm{~m}$. El listado florístico se preparó a partir de la recolección de material botánico durante el muestro de campo en el área de estudio. Los ejemplares recolectados fueron herborizados, identificados e incluidos en la colección del herbario de la Universidad Autónoma Agraria Antonio Narro (ANSM). La información de campo sirvió para estimar los atributos de la vegetación. Para cada especie de los estratos arbustivo y arbóreo se calcularon valores de densidad, cobertura o área basal y frecuencia dentro de las asociaciones del bosque de encino; con la suma de los valores relativos de estas variables se calculó el Índice de Dominancia Relativa o Valor de Importancia Relativa por especie (Mueller-Dombois y Ellenberg, 1974). Con la finalidad de obtener la ordenación estadística de las asociaciones del bosque de encino, la información de densidad relativa de las especies leñosas y variables ambientales (altitud, exposición y tipo de suelo) se sometió a un análisis canónico de correspondencia (CCA) (Ter Braak, 1986, 1987) mediante el programa CANOCO 4.0 para Windows (Ter Braak y Smilauer, 1998). Para cuantificar y expresar la diversidad alfa (Whittaker, 1972) de especies (H') de las asociaciones del bosque de encino, se utilizó el índice de diversidad de Shannon-Wiener (Krebs, 1972; Peet, 1975; Magurran, 1988), que es el más utilizado en estudios ecológicos (Magurran, 1988):

$$
\mathrm{H}^{\prime}=p \mathrm{i}(\ln p \mathrm{i})
$$

donde $p$ i es la densidad o frecuencia relativa de las especies en cada sitio de muestreo. En la estimación de la diversidad se utilizaron logaritmos naturales (Magurran, 1988; Margalef, 1991), por lo cual el índice se expresa en "nats" (Pielou, 1969).

La estimación de la diversidad de plantas leñosas por sitio se basó en la densidad relativa, mientras que para estimar la diversidad regional (diversidad gamma), así como la de cada asociación (diversidad alfa), se utilizaron las frecuencias relativas de todas las especies (árboles, arbustos y hierbas) que integran las comunidades muestreadas. Para evaluar la significancia de las diferencias entre los valores de diversidad del índice de Shannon-Wiener en las dos asociaciones del bosque de encino, se realizó una prueba de $t$ de Student, de acuerdo con la propuesta de utilización del procedimiento clásico, pero utilizando los valores del índice obtenido para cada bosque, y no valores estimados de la media; los fundamentos estadísticos de la prueba se presentan en Magurran (1988). La riqueza de especies fue medida y analizada en términos del número de especies (Peet, 1974), quien considera que la riqueza de especies es un indicador sencillo y fácilmente interpretable de la diversidad biológica. Se calculó la distribución numérica de las especies (E) como una medida de la uniformidad en la abundancia relativa de las especies en cada parcela (Pielou, 1966):

$$
\mathrm{E}=\mathrm{H}^{\prime} / \mathrm{H}^{\prime}{ }_{\max }=\mathrm{H}^{\prime} / \mathrm{lnR}^{\prime}
$$

en donde $\mathrm{H}^{\prime}$ es la diversidad observada de la comunidad y $\mathrm{H}_{\text {max }}$ es la diversidad máxima potencial, la cual se estima a través del logaritmo natural del número de especies. Con el propósito de comparar la diversidad de las dos asociaciones del bosque de encino, se utilizaron el Coeficiente de Semejanza de Jaccard:

$$
\text { CS Jaccard }=\mathrm{c} /(\mathrm{a}+\mathrm{b}-\mathrm{c})
$$

y el Coeficiente de Comunidad de Pielou (Pielou, 1975):

$$
\text { CC Pielou }=200(\mathrm{c}) / \mathrm{a}+\mathrm{b}
$$

donde: $\mathrm{a}=$ número de especies encontradas en la comunidad $\mathrm{A}, \mathrm{b}=$ número de especies presentes en la comunidad $\mathrm{B}, \mathrm{y} \mathrm{c}=$ el número de especies comunes entre $\mathrm{A}$ y $\mathrm{B}$.

Con el propósito de obtener un modelo del continuo de valores de precipitación y temperatura media anual, a partir de los cuales obtener una estimación de estas variables en los sitios de muestreo, se realizó una interpolación por regresión lineal múltiple: con base en los valores de precipitación y temperatura media anual de las estaciones más cercanas a la Sierra de Zapalinamé y calculando los valores medios anuales de una serie de datos de precipitación y temperatura de los 10 últimos años, se obtuvieron los valo- 
res de precipitación y temperatura media anual para considerarlas a ambas como variables dependientes (Y) en su correspondiente modelo. Las variables independientes consideradas en el análisis fueron altitud $\left(\mathrm{X}_{1}\right)$, latitud $\left(\mathrm{X}_{2}\right)$ y longitud $\left(\mathrm{X}_{3}\right)$, y utilizando el módulo MULTIREG de IDRISI® Kalimanjaro V.14.0, se obtuvieron los modelos que permitieron hacer para cada punto del territorio (conocida su altura media sobre el nivel del mar, su longitud y latitud) una estimación del valor de precipitación y temperatura media anual, permitiendo éstas hacer una representación continua de las variaciones de estas normales climatológicas en la región de la sierra de Zapalinamé. Con esta información se realizó un análisis de regresión lineal simple para determinar la diversidad de especies leñosas a través de gradientes de altitud, temperatura y precipitación, usando los índices de diversidad por sitio y las mediciones indirectas del clima, considerando que la altitud condiciona la precipitación y la temperatura.

\section{Resultados}

Distribución de los bosques de encino. En el área de estudio los bosques de encino se restringen a sitios con mayor humedad, como los fondos de cañones y las laderas bajas y medias con exposición norte, en altitudes de 2,000 a 2,600 $\mathrm{m}$, en donde el clima va desde templado semiseco hasta templado subhúmedo, la precipitación varía entre 309 y $334 \mathrm{~mm}$, y la temperatura media anual oscila entre 15.6 y $17.2^{\circ} \mathrm{C}$. La pendiente del terreno donde se presentan dichos bosques varía entre 15 y $50 \%$.
La asociación del bosque de encino denominada Quercus greggii-Q. mexicana se desarrolla en laderas con exposiciones norte y sigue el cauce de los escurrimientos intermitentes del cañón de San Lorenzo y otros cañones con mayor altitud y mejores condiciones de humedad. Los suelos son Regosol y el clima templado subhúmedo. Las dos especies de encino arriba mencionadas comparten la dominancia fisonómica con Pinus greggii Engelm. ex Parl., si bien esta conífera es escasa. $Q$. greggii es la especie más abundante en este bosque y crece desde 2,250 hasta 2,600 $\mathrm{m}$, piso altitudinal donde presenta los mayores valores de importancia (figura 2). Esta especie forma bosques bajos y densos, y con el aumento de la altitud disminuye su abundancia y su altura. $Q$. mexicana y $Q$. rugosa Née son árboles más altos y de copa más amplia en comparación con $Q$. greggii. La especie $Q$. rugosa tiene aquí una distribución restringida al área de Tres Caminos (2,350(2,450 m), mientras que la distribución de $Q$. mexicana es más amplia, alcanzando su mayor abundancia en altitudes por arriba de 2,300 m. Entre 2,450 y 2,600 m, Q. sideroxyla Humb. et Bonpl. forma parte de esta asociación. Otras especies que integran estos bosques son Arbutus xalapensis Kunth y Juniperus flaccida Schltdl., que aunque frecuentes, son poco abundantes.

La otra variante reconocida del bosque de encino es la asociación dominada por $Q$. saltillensis-Q. laeta. Ésta se presenta en los cañones de la exposición noroeste de la sierra conocida como El Frente y en sitios de baja elevación (2,000-2,350 m) del cañón de San Lorenzo, donde el clima es templado semiseco. Ambas especies de encino tienen los

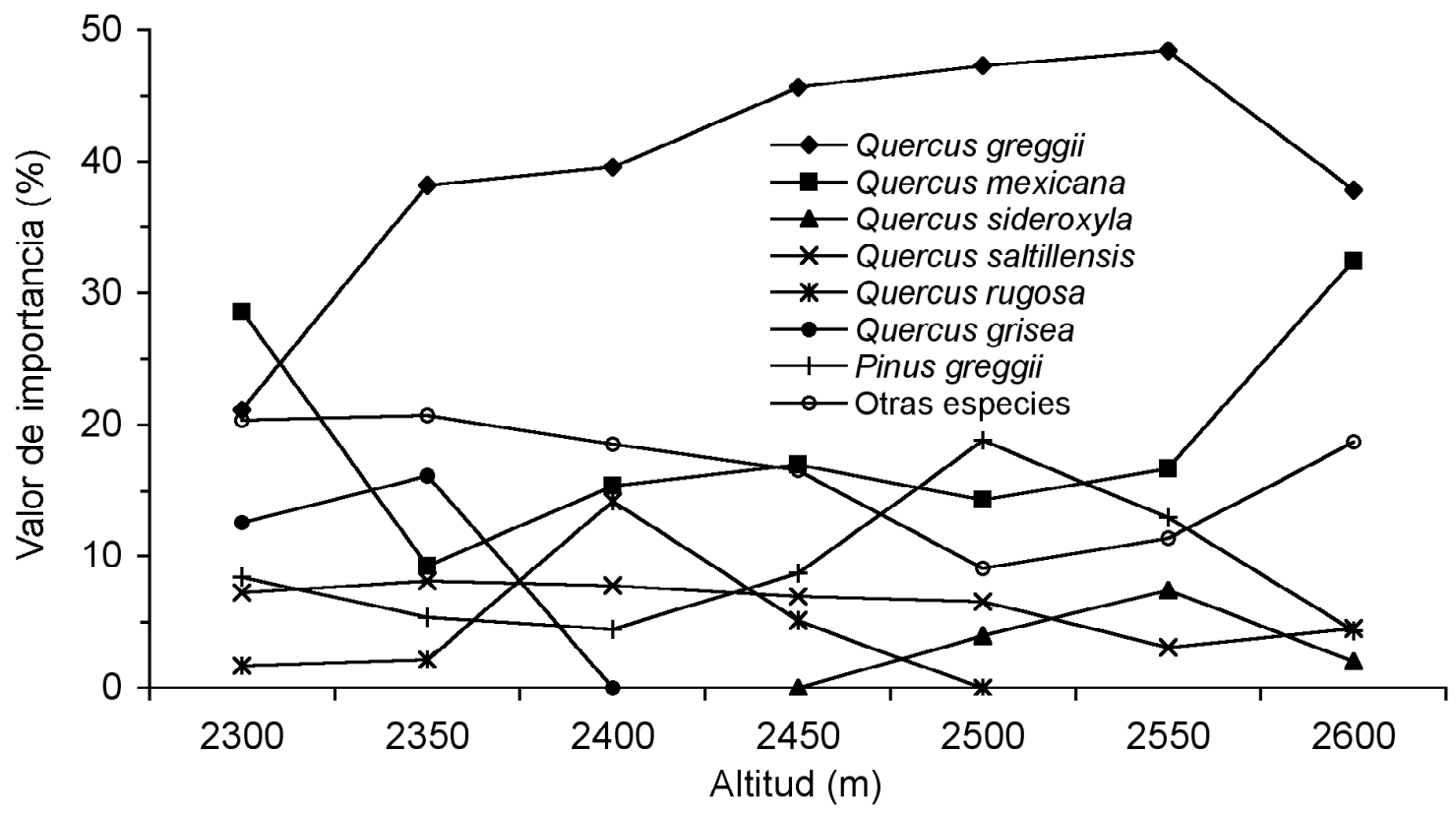

Figura 2. Valores de importancia relativa de especies arbóreas a lo largo del gradiente altitudinal en el bosque de Quercus greggii-Q. mexicana. 


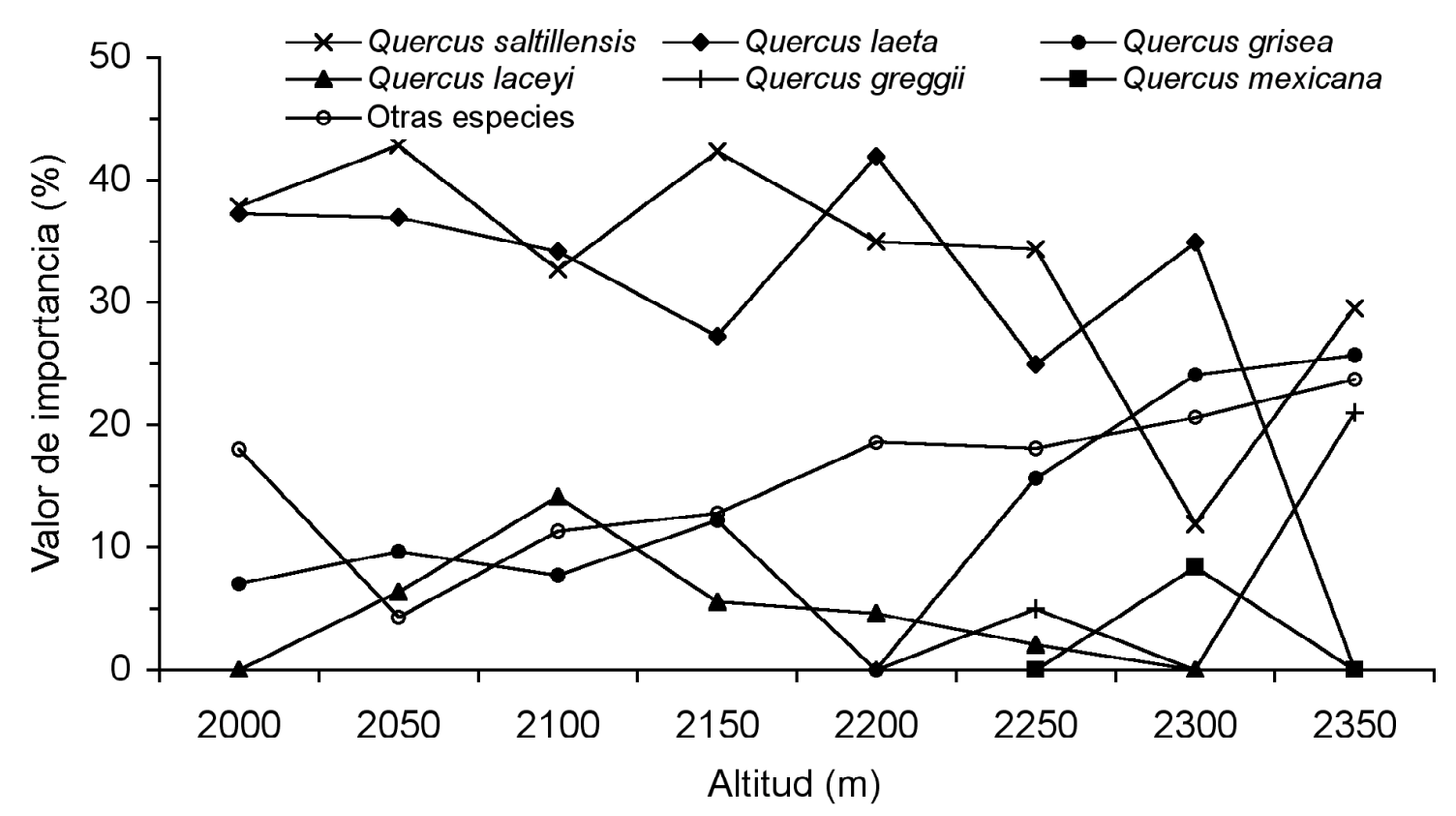

Figura 3. Valores de importancia relativa de especies arbóreas a lo largo del gradiente altitudinal en el bosque de Quercus saltillensis-Q. laeta.

valores de importancia más altos (figura 3); se trata de un bosque bajo con alturas de 6-8 $\mathrm{m}$ y una menor riqueza arbórea. Su distribución se restringe a los cañones o corrientes intermitentes; el suelo es Litosol. Q. saltillensis es la especie más frecuente en los bosques de la sierra de Zapalinamé; en altitudes menores donde se presentan encinares abiertos y en transición con el matorral submontano se asocia con $Q$. laeta y $Q$. grisea Liebm. Arriba de 2,350 m forma parte del bosque de Q. greggii-Q. mexicana; $\sin$ embargo, a altitudes mayores disminuye su dominancia. Otras especies frecuentes en este bosque son $Q$. grisea, Juniperus flaccida y Arbutus xalapensis, mientras que $Q$. greggii y $Q$. laceyi Small tienen poblaciones poco densas.

Riqueza de especies. La flora de los bosques de encino de la sierra de Zapalinamé está integrada por 259 especies, distribuidas en 177 géneros y 67 familias. Las familias mejor representadas fueron Asteraceae (61 taxa), Poaceae (27), Fabaceae (16) y Rosaceae (12). El número de especies leñosas fue de 68; de éstas, 20 fueron árboles (11 son especies del género Quercus, lo que representa $55 \%$ del estrato arbóreo), 24\% fueron coníferas y el resto correspondió a otras especies latifoliadas. Las especies arbóreas más abundantes en los bosques fueron $Q$. greggii, $Q$. saltillensis, $Q$. laeta y $Q$. mexicana, y asociadas a éstas estuvieron Arbutus xalapensis, Juniperus flaccida y Pinus greggii. El estrato arbustivo estuvo integrado por 54 especies, siendo Ageratina saltillensis (B.L.Rob.) R.M.King et H.Rob., A. ligustrina (DC.) R.M.King et H.Rob., Stevia berlandieri A.Gray, Garrya glaberrima Wangerin, G. ovata Benth., Paxistima myrsinites (Pursh) Raf. y Salvia regla Cav. las más abundantes. Otros arbustos frecuentes propios de matomales adyacentes fueron Amelanchier denticulata (Kunth) K.Koch, Agave gentryi B.Ullrich, Cercocarpus montanus Raf., Bouvardia ternifolia (Cav.) Schltdl. y Gymnosperma glutinosum Less. Se registraron 171 especies de hierbas, siendo siete las más frecuentes: Artemisia ludoviciana Nutt., Pleopeltis guttata (Maxon) E.B.Andrews et Windham, Cheilanthes tomentosa Link, Achillea millefolium L., Bromus anomalus Rupr. ex E.Fourn., Piptochaetium fimbriatum (Kunth) Hitchc. y Salvia glechomaefolia Kunth. En bosques con mayor perturbación, las hierbas dominantes fueron Smallanthus uve dalia (L.) Mack., Astragalus greggii S.Watson y Heliopsis parvifolia A.Gray. Se registraron 15 especies de helechos, entre los que Pleopeltis guttata, Cheilanthes tomentosa, $C$. pyramidalis Fée y Asplenium monanthes L. fueron los más abundantes.

Diversidad de especies. En el cuadro 1 se muestra la diversidad (índice de Shannon - Wiener) para las dos asociaciones del bosque de encino. Estos valores fueron significativamente diferentes $(P<0.001)$, siendo el bosque de $Q$. sal tillensis-Q. laeta más diverso que el bosque de Q. greg gii-Q. mexicana. Respecto a la diversidad beta o diferenciación entre comunidades, hubo 117 especies comunes a ambos bosques, lo que equivalió a un coeficiente de comunidad de Pielou de 66 (recambio de especies de 66\% [ = 0.66], mientras que el coeficiente de similitud de Jaccard fue de 0.49 . La asociación de $Q$. saltillensis-Q. laeta presentó la mayor riqueza de hierbas y arbustos (cuadro 2), así como la mayor diversidad de especies (cuadro 1). La rique- 
Cuadro 1. Diversidad de especies y equitatividad de los bosques de encino de la sierra de Zapalinamé.

\begin{tabular}{lccc}
\hline $\begin{array}{l}\text { Asociación de } \\
\text { especies }\end{array}$ & $\begin{array}{c}\text { Índice de } \\
\text { diversidad }\left(\mathrm{H}^{\prime}\right)\end{array}$ & $\begin{array}{c}\text { Diversidad } \\
\text { máxima } \\
\left(\mathrm{H}^{\prime} \text { max }\right)\end{array}$ & $\begin{array}{c}\text { Equitatividad } \\
(\mathrm{E})\end{array}$ \\
\hline $\begin{array}{l}\text { Bosque de encino } \\
\text { (diversidad gamma) }\end{array}$ & 4.961 & 5.476 & 0.905 \\
$\begin{array}{l}\text { Bosque de } \\
\text { Quercus greggii - }\end{array}$ & 4.518 & 5.037 & 0.897 \\
$\begin{array}{l}\text { Q. mexicana } \\
\text { Bosque de } \\
\text { Quercus saltillensis - }\end{array}$ & 4.920 & 5.308 & 0.927 \\
Q. laeta & & & \\
\hline
\end{tabular}

Prueba de $t$ entre asociaciones: $t=13.269 ;$ g.l. $=2371 ; P<0.05$.

za de plantas vasculares para los bosques de $Q$. greggii- $Q$. mexicana y de $Q$. saltillensis-Q. laeta fue de 154 y 202 especies, respectivamente; esta variación estuvo en su mayor parte influenciada por las hierbas, mientras que las especies leñosas no mostraron un patrón bien diferenciado. Los valores de diversidad (índice de Shannon-Wiener), diversidad máxima y repartición se muestran en el cuadro 1; el índice de diversidad fue más alto (4.92 nats) para los bosques de $Q$. saltillensis-Q. laeta y más bajo (4.51 nats) para el de $Q$. greggii-Q. mexicana. La diversidad gamma del bosque de encino de la sierra de Zapalinamé fue de 4.96 nats, con una diversidad máxima de 5.47 y una equitatividad de 0.91 .
Cuadro 2. Riqueza de especies de los bosques de encino de la sierra de Zapalinamé

\begin{tabular}{lccc}
\hline $\begin{array}{l}\text { Asociación de } \\
\text { especies }\end{array}$ & $\begin{array}{c}\text { No. de } \\
\text { especies }\end{array}$ & $\begin{array}{c}\text { No. de } \\
\text { especies } \\
\text { leñosas }\end{array}$ & $\begin{array}{c}\text { No. de } \\
\text { especies } \\
\text { herbáceas }\end{array}$ \\
\hline $\begin{array}{l}\text { Bosque de encino } \\
\text { (riqueza total) }\end{array}$ & 239 & 68 & 171 \\
$\begin{array}{l}\text { Bosque de } \\
\text { Quercus greggii - }\end{array}$ & 154 & 50 & 102 \\
$\begin{array}{l}\text { Q. mexicana } \\
\text { Bosque de } \\
\text { Quercus saltillensis - } \\
\text { Q. laeta }\end{array}$ & 202 & 58 & 143 \\
\hline
\end{tabular}

Diversidad y riqueza de especies a través del gradiente de altitud. Los valores de diversidad de especies vasculares a través del gradiente de altitud se muestran en la figura 4 . La tendencia general fue de disminución de la diversidad conforme aumentó la altitud. La diversidad media fue de 4.34; el valor máximo (4.60) se presentó a 2,100 m y el valor más bajo (4.03) a 2,500 m. La equitatividad en los bosques de encino (figura 4) tuvo valores superiores a 0.93 ; el máximo (0.98) correspondió a los sitios ubicados a 2,600 m, y la media fue de 0.97. Los bosques ubicados entre 2,400 y 2,500 $\mathrm{m}$ tuvieron una menor equitatividad y una riqueza de 119 especies; en ellos, Q. greggii y el helecho Pleopeltis guttata fueron las especies dominantes en los estratos arbó-

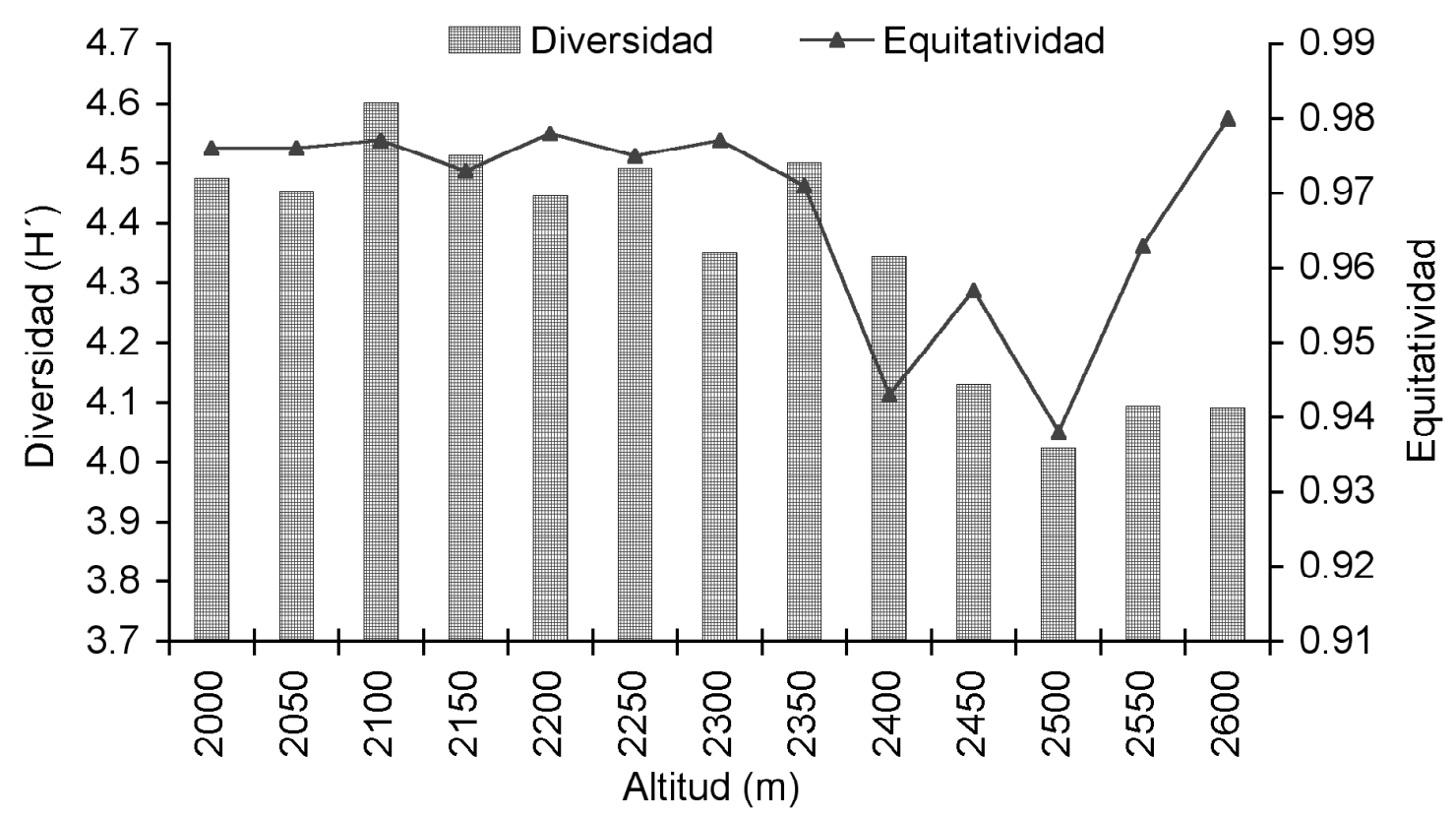

Figura 4. Distribución de la diversidad de especies y la equitatividad a través del gradiente altitudinal en los bosques de encino de la sierra de Zapalinamé. 

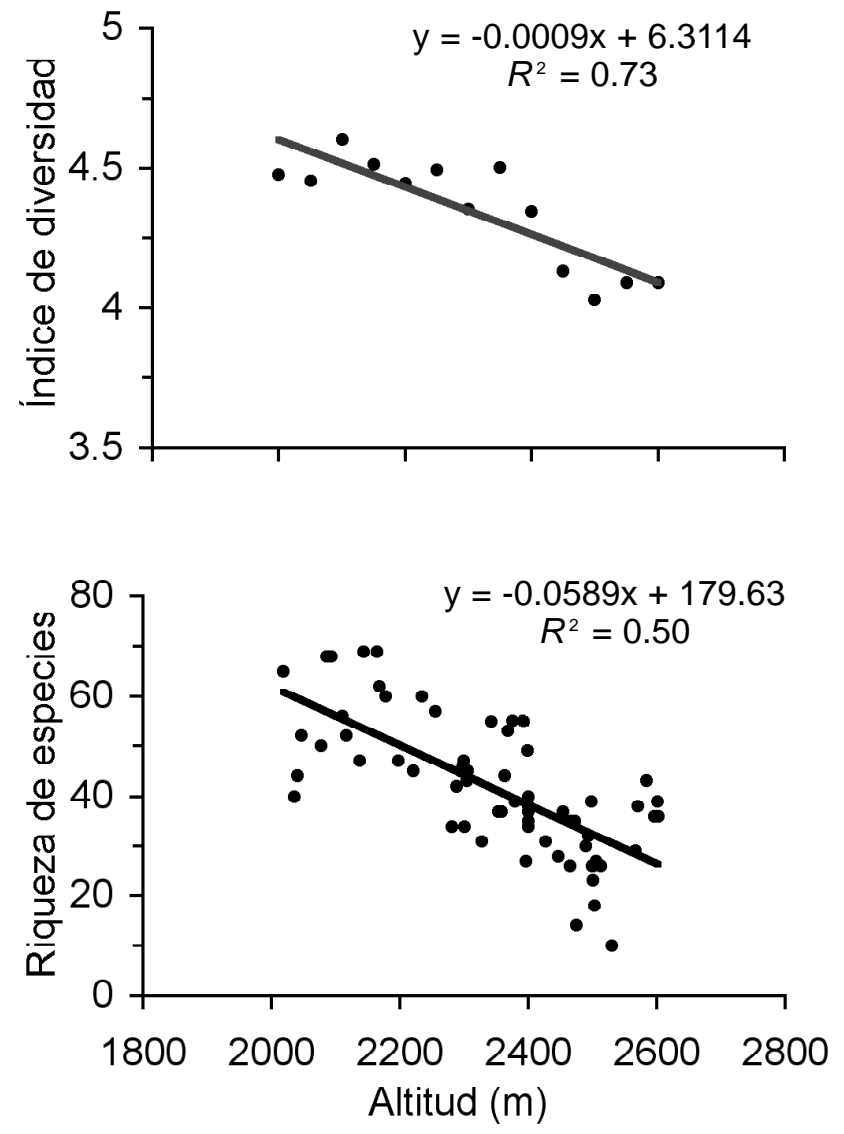

Figura 5. Diversidad y riqueza de especies del bosque de encino a través del gradiente de altitud.

reo y herbáceo, respectivamente. Otras plantas leñosas frecuentes fueron Stevia berlanderi, Ageratina saltillensis y Arbutus xalapensis.

Los bosques de $Q$. greggii-Q. mexicana se desarrollan a mayores altitudes, por lo que éstos albergan una menor diversidad y una menor riqueza de especies vasculares, en comparación con el bosque de $Q$. saltillensis-Q. laeta, propio de cañones con menor altitud. Sin embargo, los primeros tienen una mayor riqueza arbórea, la cual se incrementó de 7 a 11 especies, en un intervalo altitudinal de 2,000 a 2,600 m, ya que a esta comunidad convergen especies arbóreas del bosque de pino y oyamel, además de que este gremio es favorecido por las mayores condiciones de humedad de los cañones con clima templado subhúmedo. En el análisis de regresión, las vari ables elevación, temperatura y p recipitación explicaron, en part e, la riqueza y la diversidad de especies: la diversidad y el número de especies de los bosques de encino estuvieron relacionados negativamente con la altitud (figuras 5,6) y con la precipitación (figura 6). En general, la dive rsidad disminuyó con la altitud, pero aumentó de forma lineal con la temperatura (figuras 5, 6).

La riqueza de especies (diversidad alfa) promedio para las parcelas de muestreo fue de 40 . La riqueza tuvo su valor máximo (69 especies) a 2,150 m y disminuyó hasta 10 especies a 2,550 m (figura 5). Por su parte, la riqueza de plantas leñosas en el bosque de encino fue de 68 especies. La diversidad por sitio de muestreo se incrementó desde un índice de 1.09 nats (que incluye siete especies) a 2,570 m de altitud, hasta 2.79 (con 26 especies) a $2,150 \mathrm{~m}$ de altitud (figura 6). El índice de diversidad medio fue de 2.06, mientras que la equitatividad media fue de 0.75 .

\section{Discusión}

Distribución y caracterización ecológica de los bosques de encino. La distribución de Quercus greggii, Q. mexicana y $Q$. laeta se extiende desde el centro del país hasta el sureste de Coahuila, a través de la Sierra Madre Oriental (Zavala, 1995; Calderón y Rzedowski, 2001), mientras que $Q$. saltillensis es endémico del sureste de Coahuila (Encina-Domínguez y Villarreal-Quintanilla, 2002). $Q$. greggii y $Q$. mexicana son los encinos más frecuentes en los bosques, y al igual que en el Valle de México, forman encinares bajos (Calderón y Rzedowski, 2001). En encinares del estado de Hidalgo, $Q$. greggii y $Q$. mexicana coexisten en algunos sitios; sin embargo, la primera especie se asocia con mayor frecuencia a Q. rugosa (Zavala, 1995). En bosques de pino-encino de Santiago, N.L., Q. mexicana se asocia con Pinus greggii (Valdez-Tamez y AguilarEnríquez, 1983), mientras que Arbutus xalapensis es común además en los bosques de encino del centro y norte de México (Valdez-Tamez y Aguilar-Enríquez, 1983; Muller-Using, 1994; Zavala, 1995; Wood et al., 1999). La comunidad de $Q$. saltillensis-Q. laeta se presenta, además, en la sierra de Arteaga y la Concordia, en el sur de Coahuila (Encina-Domínguez, 1996), pero es más abundante en la sierra de Zapalinamé.

Los encinares de México se desarrollan en altitudes de hasta 2,800 m (González-Elizondo et al., 1993; Wood et al., 1999), en sitios con temperaturas medias anuales de 12 a $20^{\circ} \mathrm{C}$ y precipitación de entre 600 y $1,200 \mathrm{~mm}$ (Rzedowski, 1978). Ante esto, los bosques de la sierra de Zapalinamé (que crecen en sitios con $324 \mathrm{~mm}$ de precipitación) constituyen el extremo inferior en el gradiente de precipitación registrado para encinares mexicanos. Los bosques del centro-sur de Nuevo León se desarrollan en áreas con clima semicálido subhúmedo, entre 600 y $2,600 \mathrm{~m}$ de altitud, donde la precipitación fluctúa entre 600 y 1,080 mm anuales (Valdez-Tamez y Aguilar-Enríquez, 1983; Muller-Using, 1994). La distribución de los encinares de nuestra área de estudio contrasta con esta información; si bien el extremo máximo de altitud coincide (en parte), los autores arriba citados mencionan un marcado incremento en la humedad, lo cual contrasta con lo encontrado en Zapalinamé. La exposición y la posición topográfica influyen en la distribución de los encinos; estos factores del microrrelieve están relacionadas con gradientes de hume- 

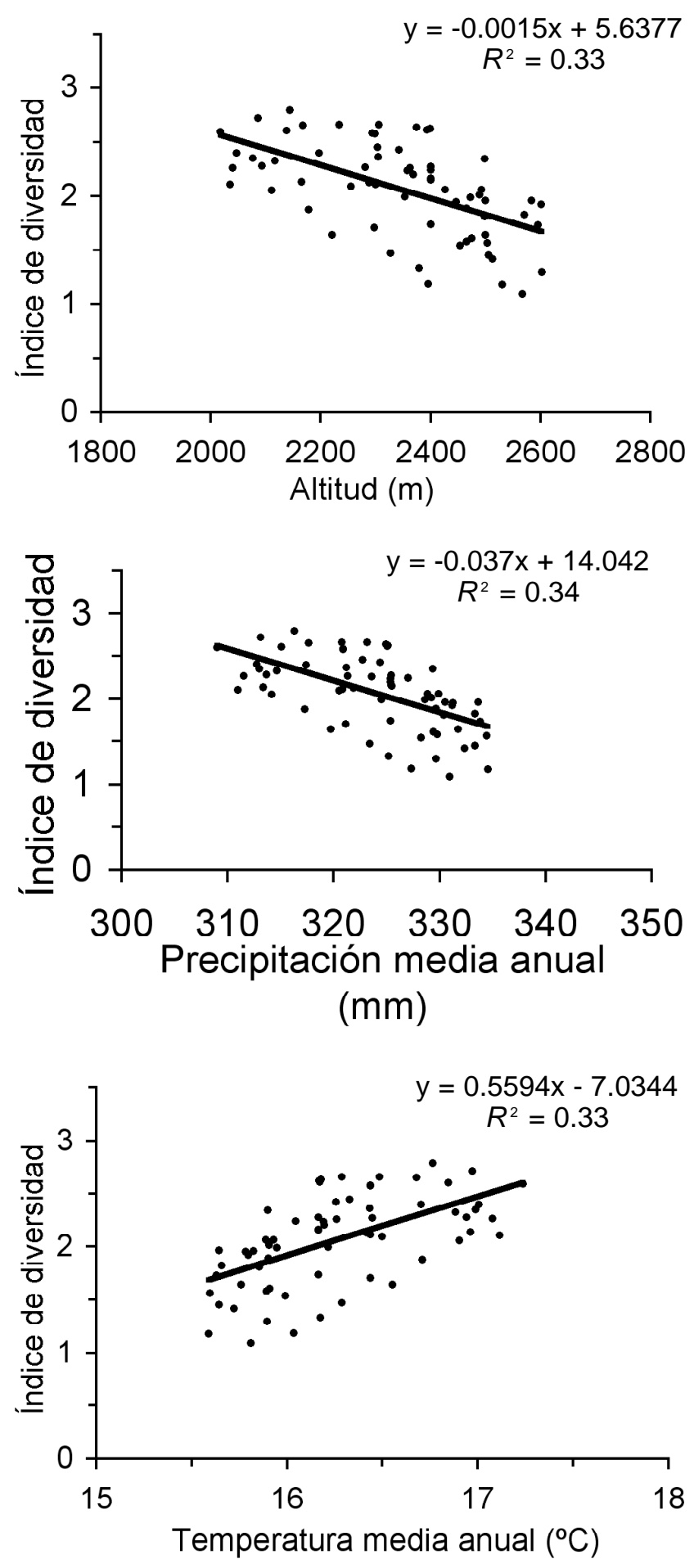

Figura 6. Diversidad de especies leñosas del bosque de encino a través de tres gradientes ambientales (altitud, precipitación y temperatura media anual). dad. A mayor pendiente y en laderas altas, Q. greggii tiene un crecimiento arbustivo (Encina-Domínguez y VillarrealQuintanilla, 2002), de modo que este bosque es reemplazado por mat orral de encinos. Al igual que en otros encinares de México, los suelos que predominan en los bosques son Litosol y Regosol, con profundidad de 15 a $30 \mathrm{~cm}$, arcillosos, café oscuro y con abundante hojarasca (Rzedowski, 1978). Los afloramientos rocosos son frecuentes y la pendiente es más o menos pro nunciada y de relieve algo ondulado.

Riqueza y diversidad de especies. Como sucede en los bosques de la Sierra de Manantlán, Jalisco, la familia Asteraceae hace la mayor contribución a la riqueza de especies (Vázquez-G. y Givnish, 1998), la cual tiene variaciones en su abundancia y diversidad a través del gradiente de altitud. Según Rzedowski (1978), en los encinares de México las plantas vasculares mejor representadas pertenecen a Asteraceae, Poaceae y Fabaceae. Gentry (1988) encontró que los bosques de zonas templadas son muy semejantes entre sí en su riqueza de especies leñosas, pero que ésta difiere significativamente de la de bosques propios de zonas tropicales (Gentry, 1988).

La alta riqueza de hierbas es semejante a la reportada para un bosque subtropical por Barik et al. (1992), quienes encontraron una diversidad alfa mayor para las hierbas que para los arbustos. El fuerte contraste en la riqueza de los diferentes gremios de plantas fue destacado para un bosque mésico por Harcome y Marks (1977), quienes señalaron una elevada riqueza de especies arbustivas y herbáceas, pero una riqueza arbórea baja. En coincidencia con lo reportado por Vetaas (1997), la diferencia entre la riqueza de especies vasculares del bosque de $Q$. greggii-Q. mexica na y el de $Q$. saltillensis-Q. laeta está en su mayor parte influenciada por las hierbas, mientras que las especies leñosas no mostraron un patrón bien diferenciado.

Los encinares de la sierra de Zapalinamé están bajo la influencia continua de impactos antropogénicos, y con frecuencia la presión humana ha ocasionado disturbios (sensu Pickett et al., 1989). En zonas boscosas y selváticas, después de disturbios como incendios (De Grandpré et al., 1993), apacentamiento, desmontes y ap rovechamientos forestales, los arbustos y las hierbas colonizan rápidamente los sitios perturbados (Rey-Benayas, 1995), incrementando su riqueza (Albert y Barnes, 1987; Gillespie et al., 2000; Schumann et al., 2003) y diversidad (Roberts y William, 1995), y afectando la distribución numérica de las especies (McMinn, 1992). La incidencia de incendios superficiales en el área de estudio (Portes, 2001), facilita la invasión y el repoblamiento abundante de hierbas (Hobbs y Huenneke, 1992), procesos que son más sensibles a la disponibilidad temporal de nutrimentos en el suelo (Bormann y Likens, 1979; Gilliam, 1988; Hutchinson et al., 1999) y que propician cambios en la composición e incremento de 
la riqueza de plantas herbáceas. Por otra parte, el apacentamiento del ganado ha contribuido a incrementar la riqueza de hierbas, ya que propicia la diseminación y el establecimiento de especies invasoras. El carácter selectivo de esta actividad promueve la desaparición de algunas especies y su reemplazo por especies ruderales (Hobbs y Huenneke, 1992); además, provoca la disminución de la riqueza y la diversidad de hierbas perennes y nativas (Pettit et al., 1995). En contraste, en otras áreas del bosque ha propiciado la disminución en la riqueza de hierbas.

Los altos valores de diversidad y la riqueza de especies del bosque de $Q$. saltillensis-Q. laeta se ajustan a la hipótesis de disturbio intermedio (Connell, 1978; Hobbs y Huenneke, 1992; Vetaas, 1997), la cual sostiene que a niveles moderados de disturbio estas variables alcanzan sus valores máximos. Sin embargo, los disturbios incrementan las posibilidades de invasión de especies ruderales e introducidas (Hobbs y Huenneke, 1992). Para bosques de encino de la cordillera de los Himalaya, Nepal, sometidos a un régimen de disturbio intermedio, Vetaas (1997) reportó una gran riqueza de plantas, en especial de hierbas, así como la presencia de especies ruderales. Los valores más altos de riqueza y diversidad corresponden al bosque de $Q$. salti llensis-Q. laeta, lo cual parece deberse, en parte, a la continua incidencia de disturbios antropogénicos. Aunque las condiciones ecológicas son determinantes de la diversidad de una comunidad, se debe considerar también la influencia de la diversidad regional y de los procesos históricos (Ricklefs, 1987). El patrón observado es consistente con lo encontrado por Bormann y Likens (1979), según quienes la riqueza de especies es más alta en áreas con intervenciones recientes y disminuye a valores mínimos en estados sucesionales avanzados, y con lo reportado por Houston (1998), quien reportó un aumento de la diversidad a través del tiempo y su disminución en estadios serales avanzados. Este patrón implicaría que el bosque de $Q$. saltillensis- $Q$. laeta presenta estadios serales iniciales o intermedios, mientras que el de $Q$. greggii-Q. mexicana sería considerado como serales medianamente tardíos, puesto que la riqueza de especies tiene su valor máximo en bosques que transitan por etapas serales intermedias (Peet y Christensen, 1980).

Finalmente, la diversidad y la riqueza del bosque $Q$. sal tillensis-Q. laeta están relacionadas con las amplias zonas transicionales hacia el matorral submontano, en donde confluyen especies de dichos matorrales. Debido al efecto de borde, las áreas de transición entre comunidades poseen mayor riqueza (Hansen et al., 1988). Además, la riqueza de especies se debe, en parte, al "efecto migrante" (Shmida y Wilson, 1985), el cual se explica por las inmigraciones de especies desde el matorral submontano y el bosque de pino, proceso que incrementan la diversidad alfa y favorece la diversidad beta (Krebs, 1972). La alta diversidad beta encontrada en el área podría estar relacionada con la hete- rogeneidad ambiental tanto climática y edáfica, como la asociada con el relieve; las regiones con topografía variada incluyen hábitats diferentes (Krebs, 1972) y por lo tanto, la diversidad beta podría explicarse por la mezcla de especies de los matorrales xéricos (Marroquín, 1976) y con comunidades boscosas de clima templado (Valdez-Tamez y Aguilar-Enríquez, 1983).

Diversidad y riqueza de especies asociada a los gradientes ambientales. Los factores ambientales que influyen en la diversidad y riqueza del bosque de encino de la sierra de Zapalinamé están condicionados por la altitud, variable que refleja efectos climáticos adversos: con el aumento de la altitud decrece la temperatura, y el frío es una condición selectiva que disminuye la riqueza de especies (Whittaker, 1965). Por ello, existe un incremento de la diversidad y la riqueza de especies de altas hacia las elevaciones más bajas (Barbour et al., 1980; Gentry, 1988; Santiago-P. y Jardel-P., 1993).

La disminución de la diversidad conforme incrementa la altitud encontrada en este estudio es semejante a la observada para algunos bosques neotropicales por Gentry (1988), quien además encontró que la diversidad está influenciada por la precipitación. En bosques boreales de Columbia Británica, Canadá, la elevación condiciona la riqueza de especies, la cual disminuye, en especial en el estrato herbáceo (Rey-Benayas, 1995). Para bosques de la Sierra de Manantlán, Santiago-P. y Jardel-P. (1993) y Vázquez-G. y Givnish (1998) reportaron disminuciones de la diversidad de árboles con la altitud; además, los últimos autores mencionan que a altitudes mayores prevalecen condiciones de humedad.

La diversidad y la riqueza de especies están correlacionadas con la precipitación (Gentry, 1988; Vázquez-G. y Givnish, 1998; Kessler, 2000). A pesar de que no existen grandes diferencias en la precipitación entre los encinares estudiados, es evidente que el número de especies cambia, por lo que es probable que dicha riqueza obedezca a otras variables ambientales y a los regímenes de disturbio. La riqueza de plantas vasculares de los sitios de muestreo mostró grandes diferencias a lo largo del gradiente de altitud y, al igual que la diversidad, la riqueza de los estratos herbáceo y arbustivo disminuyó con la altitud. Esta tendencia también fue encontrada por Vázquez-G. y Givnish (1998) para los bosques de Manantlán. Por su parte, Gentry (1988) encontró que la riqueza arbórea de los bosques neotropicales se incrementa en el gradiente de precipitación. En los bosques de encino, a medida que decrece la altitud, se incrementa la riqueza de arbustos y de hierbas anuales, ya que en sitios de baja elevación es menor la cobertura del dosel, permitiendo una mayor penetración de radiación solar en el interior del bosque (Givnish, 1998, 1997). Como resultado de la mayor incidencia de sequías, incendios y disturbios antropogénicos, se favorece el establecimiento 
de arbustos de afinidad xérica (Arce y Marroquín, 1983). La riqueza promedio en las parcelas de muestreo (40 especies) contrasta con los valores de riqueza total (media $=99$ especies; intervalo 77 a 116 especies) consignada por Vetaas (1997), y el valor de 65 especies reportado por Hutchinson et al. (1999) para bosques de encino. Esta último valor se incrementa en sitios con valores intermedios de disturbio, humedad y fertilidad de suelo. Para bosques templados, Rice y Westoby (1983) citan, en promedio, menos de 50 especies. De acuerdo con estos datos, la riqueza de los encinares estudiados puede ser considerada como intermedia, aunque aumenta a menores altitudes y a mayor precipitación, temperatura y frecuencia de disturbios antropogénicos.

En los bosques estudiados hubo una variación importante en la diversidad y la riqueza de los sitios ubicados a la misma altitud. Esto puede estar relacionado con el historial de manejo del bosque (Santiago-P. y Jardel-P., 1993). No se sabe cuáles factores ambientales determinan la diversidad de especies y cómo interactúan entre ellos (Gentry, 1988), pero sin duda, los patrones de diversidad y riqueza de especies obedecen a un complejo de gradientes ambientales, entre los que destacan los de temperatura y precipitación.

Conservación de la diversidad de los bosques de encino: implicaciones. La flora vascular de los bosques de encino de la sierra de Zapalinamé representa 63\% (259) de las 409 especies y taxa infraespecíficos registrados por Arce (1980). Esto significa que éstas son las comunidades que albergan la mayor riqueza de plantas en el macizo, con lo cual contribuyen al mantenimiento de la diversidad local. Aunque los bosques de encino no incluyen taxa de distribución restringida, en ellos se presentan especies raras como las orquídeas Govenia liliacea (La Llave et Lex.) Lindl., Goodyera oblongifolia Raf. y Malaxis spp. Además, encinos como $Q$. mexicana, $Q$. rugosa y $Q$. side roxyla, todos ellos ampliamente distribuidos en México, son raros en Coahuila (Encina-Domínguez, 1996). Los encinares son el hábitat de una gran riqueza de aves y mamíferos, entre éstos el oso negro (Ursus americanus) (S. Marines Gómez, com. pers.), especie bajo estatus de conservación según la NOM-059-ECOL-2001 (SEMARNAT, 2002), y esto basta para justificar la conservación del bosque de encino. La conservación de la biodiversidad local es uno de los objetivos centrales del área protegida (Anónimo, 1996) y su manejo debe incluir medidas que garanticen la protección de la riqueza y la diversidad de especies, sobre todo de las vulnerables. Los ecosistemas de alta diversidad deben protegerse para apoyar la estabilidad de la biosfera (Margalef, 1991). Los ecólogos de la conservación consideran a la diversidad de especies y la rareza de los taxa (Margules y Usher, 1981) entre los principales criterios para la conservación de ecosistemas y para diseñar áreas naturales protegidas (Norton, 1986). La aplicación de la diversidad en la conservación se basa en la idea de que una mayor diversidad significa una calidad ecológica más alta (Magurran, 1988). Para preservar la diversidad de especies y la dinámica de los encinares, la conservación debe considerar los procesos de disturbio (Hobbs y Huenneke, 1992), ya que de continuar la presión hacia los encinares, algunas especies pueden ser susceptibles de la extinción local. Vetaas (1997) considera que el efecto del disturbio es relevante en las estrategias de conservación, en especial en áreas densamente pobladas, y que las políticas de conservación deben permitir un impacto antropogénico de baja intensidad.

\section{Agradecimientos}

El primer autor agradece el apoyo del CONACyT para realizar esta investigación, la cual forma parte de su tesis de Maestría en Ciencias. Agradecemos las facilidades brindadas en la realización del presente trabajo al herbario ANSM de la Universidad Autónoma Agraria Antonio Narro, a Jorge S. Marroquín por sus valiosas sugerencias a la primera versión del manuscrito, y a Miguel Olvera V., Edmundo García M. y Jorge Meave por sus valiosas sugerencias para mejorar su presentación. Erika Reyna O. elaboró la figura 1. Se agradece al personal del área de protección de la Sierra de Zapalinamé por su apoyo durante el trabajo de campo.

\section{Literatura citada}

Albert D.A. y Barnes B.V. 1987. Effects of clearcutting on the vegetation and soil of a sugar maple-dominated ecosystem, Western Upper Michigan. Forest Ecology and Management 18:283-298.

Anónimo. 1983. Síntesis Geográfica de Coahuila. Instituto Nacional de Estadística Geografía e Informática, Secretaría de Programación y Presupuesto, México, D.F.

Anónimo. 1996. Decreto del Área Natural Protegida, con Carácter de Zona Sujeta a Conservación Ecológica, un Área de la Serranía conocida como Zapalinamé. Periódico Oficial del Estado, Tomo CIII, No. 83, Saltillo, Coahuila.

Anónimo. 1998. Programa de Manejo de la Zona Sujeta a Conservación Ecológica "Sierra de Zapalinamé”. Universidad Autónoma Agraria Antonio Narro, Buenavista, Saltillo, Coahuila.

Arce G.L. 1980. Adición al estudio de la vegetación y la florística del cañón de San Lorenzo, Saltillo, Coah., México. Tesis. Universidad Autónoma de Nuevo León, Monterrey, N.L., 92 pp.

Arce G.L. y Marroquín J.S. 1983. Las unidades fisonómico-florísticas del Cañón de San Lorenzo, Saltillo, Coahuila, México. Biótica 10:369-393.

Barbour M.G., Burk J.H. y Pitts W.D. 1980. Terrestrial Plant Ecology. 2a ed., Benjamin/Cummings, Menlo Park, California.

Barik S.K., Pandey H.N., Tripathi R.S. y Rao P. 1992. Microenvironmental variability and species diversity in treefall 
gaps in a sub-tropical broadleaved forest. Vegetatio 103:31-40.

Bormann H.F. y Likens G.E. 1979. Pattern and Process in a Forested Ecosystem. Springer Verlag, Nueva York.

Calderón de R. G. y Rzedowski J. Eds. 2001. Flora Fanerogámica del Valle de México. 2a ed., Instituto de Ecología, A.C. y Comisión Nacional para el Conocimiento y Uso de la Biodiversidad, Pátzcuaro, Mich.

Challenger A. 1998. Utilización y Conservación de los Ecosistemas Terrestres de México. Pasado, Presente y Futuro. Comisión Nacional para el Conocimiento y Uso de la Biodiversidad, Universidad Autónoma de México y Agrupación Sierra Madre, S.C., México, D.F.

Connell J.H. 1978. Diversity in tropical rain forest and coral reefs. Science 199: 1302-1310.

De Grandpré L., Gagnon D. y Bergeron Y. 1993. Changes in the understory of Canadian southern boreal forest after fire. Journal of Vegetation Science 4:803-810.

Encina-Domínguez J. 1996. Distribución y aspectos ecológicos del género Quercus en el estado de Coahuila, México. Tesis de Licenciatura, Universidad Autónoma Agraria Antonio Narro, Buenavista, Saltillo, Coahuila, 123 pp.

Encina-Domínguez J. y Villarreal-Quintanilla J.A. 2002. Distribución y aspectos ecológicos del género Quercus (Fagaceae) en el estado de Coahuila, México. Polibotánica 13:1-23.

Flores-Villela O. y Gerez P. 1994. Biodiversidad y Conservación en México: Vertebrados, Vegetación y Uso del Suelo. 2a ed., Comisión Nacional para el Conocimiento y Uso de la Biodiversidad y Universidad Nacional Autónoma de México, México, D.F.

Gentry A.H. 1988. Changes in plant community diversity and floristic composition on environmental and geographical gradients. Annales of Missouri Botanical Garden 75:1-34.

Gillespie T.W., Grijalva A. y Farris C.N. 2000. Diversity, composition and structure of tropical dry forests in Central America. Plant Ecology 147:37-47.

Gilliam F.S. 1988. Interactions of fire with nutrients in the herbaceous layer of a nutrient-poor coastal plain forest. Bulletin of the Torrey Botanical Club 115:265-271.

Givnish T.J. 1988. Sun and shade adaptations: a whole plant perspective. Australian Journal of Plant Physiology 15:63-92.

Givnish T.J. 1997. Adaptive plant evolution on islands: classical patterns, molecular data, new insights. En: Grant P.R. Ed. Evolution in Islands, pp. 281-304, Oxford University Press, Oxford.

González-Elizondo S., González-Elizondo M. y Cortés-Ortiz A. 1993. Vegetación de la reserva de la biosfera "La Michilía", Durango, México. Acta Botanica Mexicana 22:1-104.

Harcome P.A. y Marks P.L. 1977. Understory structure of a mesic forest in southeast Texas. Ecology 58:1144-1151.

Hansen A.J., Di Castri F. y Naiman R.J. 1988. Ecotones: what and why? En: Di Castri F., Hansen A.J. y Hollands M.M. Eds. A new Look at Ecotones: Emerging International Projects on Landscape Boundaries, pp. 9-46, Biology International Special Issue 17, International Union of Biological Sciences, París.

Hobbs R.J. y Huenneke L.F. 1992. Disturbance, diversity and invasion: implications for conservation. Conservation Biology 6:324-337.

Houston M.A. 1998. Biological Diversity: the Coexistence of Species on Changing Landscapes. Cambridge University Press,
Cambridge.

Hutchinson T.F., Boerner R.E., Iverson L.R., Sutherland S. y Kennedy E. 1999. Landscape patterns of understory composition and richness across a moisture and nitrogen mineralization gradient in Ohio (U.S.A.) Quercus forests. Plant Ecology 144:177-189.

Kessler M. 2000. Elevational gradients in species richness and endemism of selected plant groups in the central Bolivian Andes. Plant Ecology 149:181-193.

Krebs J.C. 1972. Ecology: The Experimental Analysis of Distribution and Abundance. Harper \& Row, Nueva York.

Magurran A.E. 1988. Ecological Diversity and its Measurement. Princeton University Press, Princeton.

Margalef R. 1991. Teoría de los Sistemas Ecológicos. Publicaciones de la Universidad de Barcelona, Barcelona.

Margules C.R. y Usher M.B. 1981. Criteria used in assessing wildlife conservation potential: a review. Biological Conservation 21:79-109.

Marroquín J.S. 1976. Ensayos fitogeográficos: vegetación y florística del nordeste de México I. Aspectos sinecológicos en Coahuila. Revista de la Sociedad Mexicana de Historia Natural 36:69-101.

McMinn J.W. 1992. Diversity of woody species 10 years after four harvesting treatments in the oak-pine type. Canadian Journal of Forest Research 22:1179-1183.

Medina B.R. 1983. Delimitación de sitios circulares de muestreo en investigación forestal. Ciencia Forestal 8:3-25.

Mueller-Dombois D. y Ellenberg H. 1974. Aims and Methods of Vegetation Ecology. John Wiley \& Sons, Nueva York.

Muller-Using B. 1994. Contribuciones al conocimiento de los bosques de encino y pino-encino en el noreste de México. Reporte Científico No. Especial 14, Facultad de Ciencias Forestales, Unive rsidad Autónoma de Nuevo León, Linares, N.L.

Nixon K.C. 1993. The genus Quercus in Mexico. En: Ramamoorthy T.P., Bye R., Lot A. y Fa J. Eds. Biological Diversity of Mexico: Origins and Distribution. pp. 447-458, Oxford University Press, Nueva York.

Norton B.G. 1986. The Preservation of Species. Princeton University Press, Princeton.

Olvera-V. M., Moreno-G. S. y Figueroa-R. B. 1996. Sitios Permanentes para la Investigación Silvícola. Manual para su Establecimiento. Libros del Instituto Manantlán, Universidad de Guadalajara, Guadalajara.

Peet R.K. 1974. The measurement of species diversity. Annual Review of Ecology and Systematics 5:285-307.

Peet R.K. 1975. Relative diversity indices. Ecology 56:496-498.

Peet R.K. y Christensen N.L. 1980. Succession: a population process. Vegetatio 43:131-140.

Pettit N.E., Froend R.H. y Ladd P.G. 1995. Grazing in remnant woodland vegetation: changes in species composition and life form groups. Journal of Vegetation Science 6:121-130.

Pickett S.T.A., Kolasa J., Armesto J.J. y Collins S.L. 1989. The ecological concept of disturbance and its expression at various hierarchical levels. Oikos 54:129-136.

Pielou E.C. 1966. The measurement of diversity in different types of biological collections. Journal of Theoretical Biology 13:131-144.

Pielou E.C. 1969. An Introduction to Mathematical Ecology. Wiley, Londres.

Pielou E.C. 1975. Ecological Diversity. Wiley, Londres. 
Portes V.L. 2001. Evaluación del cambio de uso de suelo y del paisaje regional en la sierra Zapalinamé. Sociedades Rurales, Producción y Medio Ambiente 2:41-51.

Ramírez-M. J.C. 1998. Un sistema de información geográfica para la identificación de los determinantes de la vegetación y usos del suelo en la sierra de Zapalinamé, Coah., México. Tesis de Licenciatura. Universidad Autónoma Agraria Antonio Narro, Buenavista, Saltillo, Coahuila, 103 pp.

Rey-Benayas J.M. 1995. Patterns of diversity in the strata of boreal montane forest in British Columbia. Journal of Vegetation Science 6:95-98.

Rice B. y Westoby M. 1983. Plant species richness at the 0.1 hectare scale in Australian vegetation compared to other continents. Vegetatio 52:129-140.

Ricklefs R.E. 1987. Community diversity: relative roles of local and regional processes. Science 235:167-171.

Roberts M.R. y Gilliam F.S. 1995. Disturbance effects on herbaceous layer vegetation and soils nutrients in Populus forests of northern lower Michigan. Journal of Vegetation Science 6:903912.

Rzedowski J. 1978. Vegetación de México. Limusa, México, D.F.

Rzedowski J. 1991. Diversidad y orígenes de la flora fanerogámica de México. Acta Botanica Mexicana 14:3-21.

Santiago-P. A.L. y Jardel-P. E.J. 1993. Composición y estructura del bosque mesófilo de montaña en la sierra de Manantlán, Jalisco-Colima. Biotam 5:13-26.

Shmida A. y Wilson M. 1985. Biological determinants of species diversity. Journal of Biogeography 12:1-20.

Schumann M.E., White A.S. y Witham J.W. 2003. The effect of harvest-created gaps on plant species diversity, composition and abundance in Maine oak-pine forest. Forest Ecology and Management 176:543-561.

SEmarnat [Secretaría del Medio Ambiente y Recursos Naturales]. 2002. Norma Oficial Mexicana NOM-059-ECOL2001, P rotección ambiental-Especies nat ivas de México de flora y fauna silvestres-Categorías de riesgo y especificaciones para su indusión, ex clusión o cambio-Lista de especies en riesgo. Dianio Oficial de la Federación. 2a Sección, 6 de marzo de 2002.
Ter Braak C.J.F. 1986. Canonical correspondence analysis: A new eigenvector technique for multivariate direct gradient analysis. Ecology 67:1167-1179.

Ter Braak C.J.F. 1987. The analysis of vegetation environment relationships by canonical correspondence analysis. Vegetatio 69:69-77.

Ter Braak C.J.F. y Smilauer P. 1998. CANOCO Reference Manual and User's Guide to Canoco for Windows: Software for Canonical Community Ordination (ver. 4) Microcomputer power, Ithaca, NY.

Toledo V.M. y Ordóñez M.J. 1993. The biodiversity scenario of Mexico: a review of terrestrial habitats. En: Ramamoorthy T.P., Bye R., Lot A. y Fa J. Eds. Biological Diversity of Mexico: Origins and Distribution, pp. 757-777, Oxford University Press, Nueva York.

Valdez-Tamez V. y Aguilar-Enríquez M.L. 1983. El género Quercus en las unidades fisonómico-florísticas del municipio de Santiago, N.L., México. Boletín Técnico No. 98, Secretaría de Agricultura y Recursos Hidráulicos, México, D.F.

Valencia-A. S. 2004. Dive rsidad del género Quercus (Fagaceae) en México. Boletín de la Sociedad Botánica de México 75:33-53.

Vázquez-G. J.A. y Givnish T.J. 1998. Altitudinal gradients in tropical forest composition, structure, and diversity in the Sierra de Manantlán. Journal of Ecology 86:999-1020.

Vetaas O.R. 1997. The effect of canopy disturbance on species richness in a central Himalayan oak forest. Plant Ecology 132:29-38.

Whittaker R.H. 1965. Dominance and diversity in land plant community. Science 147:250-260.

Whittaker R.H. 1972. Evolution and measurement of species diversity. Taxon 21:213-251.

Wood S., Harper G., Muldavin E. y Neville P. 1999. Vegetation map of the Sierra del Carmen, U.S.A. and Mexico. Reporte final, U.S. Geological Survey, National Wetlands Center y National Park Service. (Inédito).

Zavala F. 1995. Encinos Hidalguenses. Universidad Autónoma de Chapingo, Chapingo, Edo. de México.

Recibido: 30 de junio de 2006

Aceptado: 26 de mayo de 2007 